others to employ protective injections against diphtheria more frequently and with undoubted benefit to their patients. I should, however, like to point out that, although the results as regards the patient may in most instances be satisfactory. there is a danger in private practice that unless the injections are combined with systematic bacteriological examination the immunised patient may possibly act as a source of infection for others, although apparently free from disease himself.

In the autumn of 1903 I examined a "swab" taken from the throat of a woman who had been attending a fatal case of diphtheria and had received a prophylactic dose of antitoxin about a fortnight previously. It yielded a typical culture of virulent diphtheria bacilli. The patient had herself been free from symptoms but three children with whom she had come into intimate contact had developed the disease. From the throat of each of them I obtained diphtheria bacilli. It is, of course, possible that there is no connexion between the two sets of cases and that the woman instead of being a "carrier," as appeared probable, was herself infected at the later date. Such an experience suggests, however, that it is advisable to take precautions and to combine the prophylactic use of diphtheria antitoxin with routine bacteriological examination until it can be proved that such injections not only protect the recipients but also the community at large.-I am, Sirs, yours faithfully,

Beaumont-street, W., May 15th, 1905.

P. J. CAMMIDGE.

\section{TETANUS AND CHLORAL HYDRATE.}

\section{To the Editors of THE LANCET.}

SIRS, - In the interesting paper by Mr. J. Maberly on the above subject in THE LANCET of May 6th, the writer mentions that he is not aware of any records of such large doses being given without adverse symptoms. It may interest him, therefore, to know that in 1874 Oré $^{1}$ injected chloral hydrate in a case of tetanus with successful results. Two intravenous injections of nine grammes each (a total of about 270 grains) were given within a short interval and the dose was repeated on the two following days. The patient passed into a profound state of anæsthesia and eventually recovered. Mr. Maberly's patient received 240 grains within 11 hours, half per os and half per rectum. Other cases are on record but they were not so favourable as Oré's original one. Cruveilhier's ${ }^{2}$ patient died during the anæsthesia, after receiving 29 grammes (435 grains) in five days. Abbe's ${ }^{3}$ patient became cyanosed after one injection of ten grammes (150 grains) and after consciousness was restored died in tetanic spasms. Oré ${ }^{4}$ subsequently used chloral hydrate intravenously as a general anæsthetic, from five to ten grammes (from 75 to 150 grains) producing an anæsthesia of about halfan-hour's duration. In all about from 30 to 40 cases are on record but the dangers of the method were eventually found far to outweigh its usefulness.

I am, Sirs, yours faithfully,

J. M. Fortescue-Brickdale, M.A., M.D. Oxon. Clifton, May 13th, 1905.

\section{BIRMINGHAM.}

(FROM OUR OWN CORRESPONDENT.)

\section{Hollymoor Asylum}

THE Rubery-hill Asylum annexe at Hollymoor was opened on May 6th by the Lord Mayor of Birmingham in the presence of a large assembly. It occupies a site of 120 acres a short distance from the existing asylum at Rubery. It comprises patients' blocks and administrative buildings, a spacious dining and recreation hall, engine and boiler houses, laundry, bakehouse, and workshops, homes for attendants, nurses, and servants, with dining and recreation rooms. There is an attractive Gothic church in the grounds, also an isolation hospital, with the necessary administrative department. As the asylum is to be treated as an annexe of the Rubery-hill Asylum no residence has been built for the medical superintendent but accommodation has been provided between the male and female sides for three assistant medical officers. Lodges have been erected at two entrances and

1 Comptes Rendus Académie des Sciences, 1874, pp. 515 and 651. 3 Société Gazette des Hopitaux, No. 49, p. 386, 1874

4 . Cha 173.1874 detached residences have been built for the engineer, the head attendant, the gardener, and eight married attendants. The building will be capable ultimately of providing accommodation for 1000 patients but blocks have only at present been erected for 604 patients. Provision for all emergencies has been made. Two rooms at the west end of the church have been provided for patients who may have an epileptic seizure during service. In each bedroom is a telephone and in the door is a window through which the attendant can readily keep a patient under complete observation. Two large tanks capable of holding 29,500 gallons of water are especially kept in reserve for fire extinguishing purposes. The bedrooms are lighted from an electric light in. the corridor so arranged that the light shines through a window above the door. The heating of the establishment is by means of low-pressure hot water pipes and radiators heated by steam calorifiers placed in the subways. The hot water supply is heated in high-pressure steam calorifiers placed in the basement of the water tower and is driven by means of pumps to the several draw-off taps. Monotony in colour scheme and decoration has been avoided as much as possible. Reading, music, and games can be indulged in and at one end of the recreation hall there is an ample stage for dramatic performances. Altogether the building is what is claimed for it-a model of its kind.

\section{The Ingleby Lectures.}

Departing from the usual custom, the Ingleby lectures were not delivered on a technical subject this year but on a subject of general interest-viz., feeble-mindedness. The lecturer was Dr. James Kerr, the advisory medical officer to the Education Committee of the London County Council. Many of the lay public who are known to be interested in social and educational matters were invited and each lecture was attended by a large and interested audience. Dr. Kerr, after paying a tribute to the memory of the founder of the lectureship, considered the definition of feeble-mindedness and the classification of the various types. He believed that the study of the mentally defective by trained experts using all the methods of psychology, physiology, and clinical medicine would be most useful and be likely to throw much light on normal brain action and development. In his concluding lecture he emphasised the importance of detecting cases of feeble-mindedness in the schools and spoke of the part which heredity, alcoholism, and phthisis played in the production of the condition. For all imbeciles and for most of the feeble-minded he advocated sterilisation at an early age.

\section{The Birmingham Lying-in Charity.}

The committee of the Lying-in Charity has issued an appeal for $£ 8000$ wherewith to build a nursing home for the training of midwives. $£ 5000$ have already been subscribed and the site has been purchased. At the home beds will be provided for certain special cases and arrangements will be made for giving the necessary instruction and enabling it to become recognised as a training centre by the Central Midwives Board. With the exception of the Birmingham workhouse infirmary, where a few midwives are trained, there is no recognised school in the district, and as it is estimated that 10,000 births are managed by midwives in the city each year it is obvious that something must be done to supply the want.

Birmingham Baths and Parks Committee.

At the last meeting of the above committee some interesting figures were given by the superintendent. Last year 621,628 persons were admitted to the baths, an increase of 104,699 bathers compared with the previous year and an increase of 208,630 when compared with 1903. No less than 89 cricket clubs have been registered to play cricket in the principal parks of the city. It is most reassuring at a time when much is said of physical degeneration to hear of so general an indulgence in healthy exercise.

Birmingham, Tame, and Rea Distriot Drainage Board.

A very satisfactory state of affairs was disclosed at the quarterly meeting of the above board. The actual income for last year was $£ 2366$ more than was estimated and the actual expenditure was $\$ 3870$ less than the estimate. In consequence it was decided to make a levy of $\frac{1}{2} d$. per tenement less than last year. The opinion was also expressed that the board had now reached the point when the normal increase of tenements and the amount of money received from them would be sufficient to meet their normal increase in the expenditure. The board further decided to do less farming in the future and to adhere more 